\title{
Lo religioso en perspectiva de identidad y pensamiento latinoamericano
}

\author{
José Antonio Segura Calvo 1 \\ Instituto de Estudios Latinoamericanos \\ Universidad Nacional, Costa Rica
}

\section{Resumen}

La religión es un elemento propio e inherente de la condición humana. Por lo tanto, lo religioso es parte de la identidad y como tal, un rasgo del pensamiento latinoamericano y una expresión del sentir y del ser en América Latina.

Palabras claves: religión, identidad, América Latina, Iglesia latinoamericana

\begin{abstract}
Religion is an inherent element of human condition. Thus, religion is part of identity and, for this reason, a feature of Latin American thought, and an expression of feeling and being in Latin American.
\end{abstract}

Key words: religion, identity, Latin America, Latin American Church

\section{Estado original}

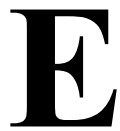
1 que no ama no es menos "hombre" que el que ama; el primero sueña con ser libre, el segundo es libre; el primero se despierta para poseer el mundo, el segundo se dona para crear humanidad; el primero teme vincularse y

1 Graduado de la Licenciatura en Estudios Latinoamericanos del IDELA. Este artículo está basado en su tesis: La evolución de la catequesis en América Latina a la luz de los documentos sinodales del CELAM: Medellín, Puebla y Santo Domingo y su influencia en la identidad cultural. no ama, el segundo sabe que es libre gracias a que puede amar. Por ello es que cada hombre y cada mujer a lo largo del espacio tiempo de una u otra forma, en más o menos medida, pacífica o despóticamente, se mueven a buscar la felicidad.

Esta búsqueda, en muchas oportunidades, se detiene porque hemos crecido creyendo que lo que nos da «confort» es la clave de nuestra seguridad, y cuando el ser humano se siente seguro olvida que su propia naturaleza no es un estado absoluto de «confort»; 
por el contrario, existe una indeterminación que lo lanza desnudo más allá del «confort» y la seguridad material, y lo pone en camino en búsqueda de su identidad.

La naturaleza humana parte de una «matriz biológica», articulada por las acciones e integraciones de los «genes reguladores» proveyéndonos de ocho pares de genes, tal y como los tienen los peces, pero desencadenando una especie diversa; es decir, podemos deducir e inducir la estructura más íntima de la «matriz biológica humana» que comparte un vínculo innegable con los demás seres que se desprenden de ella, pero no podemos decir nada sobre la necesidad espiritual y con ella la creciente añoranza de ser en el mundo más que un ser.

Esta «necesidad» es inherente a la conciencia humana, pues buscamos significar un vínculo de pertenencia, a diferencia de las otras especies.

Sabemos que crecemos en determinada dinámica social, y que como tales esta nos condiciona, pero aunque nos condiciona puede no determinar nuestra naturaleza; influye y llega incluso a condicionar nuestra forma de percibir y de significar el mundo, de hecho buscamos las respuestas preestablecidas en nuestra «conciencia pregrabada» con un modelo de ciencia que genera una ansia individual de autodeterminación, de identidad individual, siendo:

(...) el punto de partida una persona individual absolutamente sola en este mundo que, con un giro de un brazo atrapa de la nada ciertos elementos de conocimiento y busca una solución al problema de cómo estos elementos pueden realizar una tarea de transmitir conocimiento de una persona a otra. (....) Primero tendremos que librarnos de la fuerza apremiante de la costumbre (...) ha habituado a los individuos que buscan una explicación de carácter de inicio. Esa solución no es factible. La formación de un lenguaje, como la del conocimiento es un proceso continuo, es un proceso continuado sin quiebras absolutas. (Elias, 2000: 39)

Así mismo, la regulación del conocimiento en la sociedad no es otra cosa que pautas de poder; no lo interpretamos como un vehículo que nos vincula a nuestra herencia humana, por tanto, si la dimensión de religiosidad del ser humano se considera como la posesión de un conocimiento determinado que le da la clave y el poder individual de acceder a lo sagrado, esta dimensión no es más que un reflejo de la dinámica hegemónica de los sistemas de mayor poder en una sociedad, y se convierte en una manipulación más de la necesidad inherente de significación y realización de los seres humanos.

Curiosamente, se ha pensado que la búsqueda del estado original del ser humano es lo que nos devolvería la serenidad y con ella la felicidad. Entre uno de tantos y no menos ilustres pensadores tenemos a Rousseau (1755) que en su célebre obra $E l$ origen de la desigualdad entre los hombres presenta y defiende la teoría de que las artes, las ciencias y las instituciones sociales han corrompido al ser humano, y expone tácitamente que el plano moral natural es superior al que se genera en el Estado. $\mathrm{Su}$ aserto resume esta posición: 
"todo es perfecto al salir de las manos del Creador y todo degenera en la manos de los hombres", 2

[...\} pero el estado original no es forzosamente el estado mejor. La forma concreta es una manifestación, más perfecta que el átomo, y el hombre es más perfecto como hombre que allí donde se desvanece en una indefinición original. [...\} "la verdad es finita e infinita al mismo tiempo: se mueve y está, no obstante, quieta, se encuentra en lo distante y lo próximo, reside en el interior de todas las cosas y fuera de ellas". (Tagore 1998: 372).

Ante esta manifestación de accidentalidad, o en su defecto como lo declara Zea (1976: 49) "Conciencia de accidentalidad", que a Latinoamérica no le es propia o exclusiva, de la misma forma, no se puede pensar que estas preocupaciones fueron tan solo de las civilizaciones europeas, orientales o bien producto de los nuevos imperios dominadores, de las nuevas técnicas de la ciencia para explicar los fenómenos sociales; aunque todos ellos hacen aportes considerables, no son los únicos que tienen estas interrogantes.

Si viajamos a una espacialidad más cercana descubrimos que en el Popol Vuh (1976: 31) encontramos muchas referencias a nuestra constitución humana y a esta conciencia de accidentalidad, planteada

2 Otro autor es Thomas Hobbes quien dice "homo hominis lupus" (el hombre es lobo para el hombre) en su obra Leviatán que en su primera parte versa sobre el deseo de poder manifiesto en los actos, y sobre la valoración de estos en sus consecuencias por la razón humana. desde un lenguaje armónico con su cosmovisión, cuyas respuestas describen y representan una reflexión profunda de la vida misma, donde interpretan el acto creador como un proceso y el hombre como parte integral de este:

(...) $\mathrm{Y}$ al instante fueron hechos los muñecos labrados en madera. Se parecían al hombre, hablando como el hombre y poblaron la superficie de la tierra. Existieron se multiplicaron, tuvieron hijos, tuvieron hijos los muñecos de palo; pero no tenían alma, ni entendimiento, no se acordaban de su Creador, de su Formador, caminaban sin rumbo y andaban a gatas. Ya no se acordaban del corazón del cielo ${ }^{3}$ y por eso cayeron en desgracia. Fue solo un intento, (...) de hacer al hombre...,(1976)

Incluso, en nada se podría pensar que su cosmovisión difiere de las teorías modernas, tanto de la evolutiva ${ }^{4}$ y sus variaciones ${ }^{5}$, como la del «Big bang» ${ }^{6}$, la termodinámica; si acaso difieren en la articulación del lenguaje, la expresión de la tecnología, los métodos, los recursos y la especialización. Lo que al hombre moderno le ha

3 Deidad que se conforma de tres actores y que se denomina Huracán, llamado corazón del cielo, además se le identifica con la creación del hombre, lo notable es que esta creación no es por espontaneidad como le es propio de la acción de diferentes narraciones de la creación, en este caso se entiende como un proceso de prueba y error, hasta alcanzar la creación del hombre (1976: 26).

4 Charles Darwin (1963), El origen del hombre $y$ la selección en relación al sexo, 6a ed. México, Editorial Diana.

5 C. León Harris (1985), Evolución génesis y revelaciones. Madrid, Edit. Hermann Blume. Traducción Antonio Resines. Titulo original inglés: Evolution: Genesis and Revelations (1981).

6 Stephen Hawking (1988), Historia del tiempo del big bang a los agujeros negros. Barcelona, Editorial Crítica, p.73. 
costado tanto explicar en muchos de los casos, nuestras raíces ancestrales lo tenían como norma de vida $^{7}$, es la accidentalidad que se hace conciente en la fragilidad humana y sólo le es posible perpetuarse en interacción equilibrada de los diversos sistemas en busca de una armonía.

\section{Sentido de pertenencia}

Por todo ello es que existe una tensión mundial que trata de recuperar los vínculos afectivos que dan el sentido de pertenencia del individuo a un grupo determinado, vínculos que tienen la impronta de la imposición con el consecuente y gran inconveniente de encontrarnos prisioneros en los cánones estructurales que en lugar de promover, limitan el crecimiento integral del ser humano. Lo sumergen en una prisa constante, en una individualidad alienante, en una ansiedad continua de insatisfacción que en muchos de los casos representa la infelicidad tanto interna como externa, si es que cave enfatizarla de esta manera, es decir la soledad absoluta, confrontada con el crecimiento material, intelectual, social, político, tecnológico y espiritual.

Expresiones todas ellas del poder significar su realidad en el mundo, pero una realidad individual, siempre por encima de la realidad del otro, no para construir con el otro, sino para manipular al otro a favor de mis intereses.

7 Seguimos pensando que un paradigma no es superior a otro porque el otro sea falso, sino que este representa mejor la realidad y la explica, aunque no queremos decir que el que mejor explica la realidad sea el paradigma más nuevo, puede que caiga en desuso por una moda o un énfasis aunque su vigencia sea rescatada incluso siglos después de que se creía superado. En este punto nos apartamos un poco de Zidane Ziraqui (2000) y nos acercamos más a la posición de Norbert Elias (1994).
Las interrogantes se hacen cada vez más patentes en la búsqueda actual de la definición humana $\mathrm{y}$, aun más, cuando se trata de su dimensión religiosa entendida como búsqueda no como posesión de un conocimiento, que hoy por hoy nos hace alejarnos de nuestra identidad latinoamericanamente humana dejándonos en una indeterminación que angustia nuestras vidas, aunque muchos no podamos alcanzar la conciencia plena de esta insatisfacción que padecemos.

Emilia Prieto (1991: 15) nos presta el sentido profundo de esta insatisfacción, tanto como nos devela rasgos de una intuición que busca retarnos en esta construcción identitaria cuando dice: "La palabra es la luz que ilumina los siglos. Y en el juego bivalente de los contrarios, la mentira es espuria." Nos podemos aventurar e interrogarnos: ¿es la palabra la que hace aparecer la claridad del conocimiento? $\mathrm{O}$ ¿es la palabra la que oculta en su horizonte el ser y el conocer?

Es acaso que la palabra libera, o es el cómo que en este caso causa la interrogante cuando la escritora siente que se libera en el acto de producir la palabra, de significar con ella, cuando siente que fluye naturalmente y que comporta el ser en la intuición que capta lo que no se puede hacer tangible de otra forma.

Para lograr esta intuición se cree necesaria una intención, la que varía según la motivación del sujeto, la misma que cuando es alcanzada deja a la intención sin movilidad, el sujeto queda flácido, como sin vida, porque ha logrado la intuición a causa de un motivo, perdido el motivo muere la intención 
que busca la intuición. Queremos decir que la motivación genera una dependencia tanto o mayor que una droga en sentido fisiológico, pues mueve nuestra intención.

Con ello el ser humano vive de motivo en motivo, cada vez necesitando de un motivo mayor en el cual proyectarse, y creando a la vez una nueva expectativa que satisfaga y mueva su intencionalidad. Busca mantener un vínculo que le dé un sentido de pertenencia.

\section{Cultura "light" y prototipo ideal: mistificación}

La fuente donde se nutre esta forma de vivir no es la denominada «cultura liviana»; esta nos presenta un prototipo de ser que hace referencia directa a una determinada forma de comportarse, de verse, de tener sentido, la homogenización que se transmite en los anuncios, contemplados en todas las formas posibles de comunicación, un estilo de vida que nos da la posibilidad de vincularnos si fumamos esta clase de cigarrillos $^{8}$ y si consumimos este tipos de licor $^{9}$, si vistes determinada clase de vestido, si hablas y tienes tal o cual cosa, serás un triunfador, el motivo nos crea una ansiedad que nos mueve la intencionalidad.

No asistimos al gimnasio porque creemos que es bueno para la salud, sino que se convierte en un impulso compulsivo para vernos mejor y como los demás; es lo que hace mover nuestra voluntad. Cuando

8 "Algo tenemos en común", anuncios televisivos 2002, Costa Rica.

9 "Laptops de día, Bacardi de noche". Encontrado en las vallas publicitarias de las autopistas y carreteras de Costa Rica desde marzo del 2002. Se incita a un estilo de vida, a un modelo estético, en general a un modo de ser particular, dependiente. llegamos posiblemente no calcemos con el ambiente, nos sintamos inadecuados porque no tenemos los implementos $\mathrm{y}$ aditamentos deportivos óptimos, es decir no vestimos acorde con el lugar; luego comienza el maltrato físico y psicológico, nos dan estimulaciones tales como: "para que sirva tiene que doler", refiriéndose al ejercicio y a sus sacrificios con tal de lograr una buena condición física; nos preguntamos si los espejos dispuestos en todos estos centros no son más que generadores de depresiones visuales, nos hacen que nos miremos constantemente y que veamos cómo lucen los demás, cuán "be1lo" se es respecto de un prototipo ideal y no uno real. Boff (1999: 12) nos coadyuva en la comprensión de este ideal al decir:

(...) La propaganda comercial en la TV presenta el cigarrillo LS. Quien fume de esa marca tendrá parte entre los "dioses": hombres bellos, ricos en mansiones maravillosas, con mujeres deslumbrantes, excitados en el amor, con todos los conflictos solucionados (...)

Ante la angustia que se genera con estas presiones visuales y subliminales, cada vez se implementa más potencia, más fuerza, más deseo, más músculos, comenzamos con una tonificación del cuerpo, pero en realidad en el fondo se está cambiando poco a poco nuestra anatomía física, y nuestra mentalidad con del paso del tiempo tiende a preocuparse más por nuestras rutinas de ejercicio que por nuestras relaciones psicosociales y afectivas.

Se nos desinhibe la aceptación social, porque nos sentimos parte de la 
homogenización, no nos vemos diferentes, porque resultamos ser parte de un proyecto de manipulación social; somos objetos del mercado, hemos dejado de ser nosotros mismos para convertirnos en superegos, sumergidos en la vanidad de una estética, que nos presenta un concepto de «belleza» ficticio cuyo fin es consumir tanto como podamos y deseemos ser aceptados.

El hombre se ha vuelto prisionero de aquello que creó, la felicidad radica en el individualismo y en su propio interés, ya no en la realización de su vida, sino por el contrario, como lo afirma Fromm (1963: 30), en el cumplimiento de su deber que no es más que el éxito y el trabajo para alcanzarlo:

El dinero, el prestigio y el poder se han convertido en incentivos y sus metas, ahora actúa bajo la ilusión de que sus acciones benefician sus propios intereses, aunque de hecho sirve a todo lo demás, menos a los intereses de su propio ser. Todo tiene importancia para él, excepto su vida y el arte de vivir. Existe para todo, menos para sí mismo.

El ser humano, en su búsqueda de la felicidad, no alcanza a discernir ni a desarrollar su capacidad de discernimiento ético, se mueve dentro de unos parámetros preestablecidos, cree ilusoriamente actuar, sin ser consciente de que se mueve mistificado hacia su propia destrucción.

Cada vez queremos más, una nueva motivación nos ayuda a generar mayor cantidad de adrenalina, o simplemente una nueva angustia generada por una nueva ansiedad ficticia, impuesta; si no poseemos, dejamos de hacer, dejaremos de ser, retornaran las depresiones y los infraegos.

Es una búsqueda constante de vinculación pero que no tiene ningún asidero social; Enrique Rojas (1994: 17) acota que:

(...) se trata de un hombre sin vínculos de compromiso, en el que la indiferencia estética se alía con la desvinculación de casi todo lo que lo rodea. Un ser humano rebajado a la categoría de objeto, repleto de consumo y bienestar, cuyo fin es despertar admiración o envidia.

Esta misma dinámica la podemos aplicar a los diferentes círculos clasistas que generan estatus en nuestras sociedades, con el fin de que sus miembros se afilien y tengan sentido de pertenencia. Se puede ser graduado de alguna universidad, tener títulos académicos, pero poseerlos no representa necesariamente una madurez intelectual y humana de productividad, pero de alguna forma nos hace pertenecer, hecho que parece ser suficiente, pertenecer a un equipo o grupo de las más variadas definiciones.

Así mismo, mantener la "belleza" es toda una empresa; se trabaja para que nos mantengan acicalados, los salones de "belleza" se convierten en nuestros segundos hogares, no podemos pasar una semana lejos, y sufrimos amargamente cuando nuestro estilista está enfermo o se toma unas vacaciones, parece que se nos acaba el mundo. Quién me va a escuchar y quién me dará ese trato especial, porque me siento tan bien y feliz, aseguran. 
Cuando alguno de estos núcleos de control, o centros de soledad individualista no está para nosotros, no le encontramos sentido a lo que hacemos, ni a lo que somos, ni al dinero que ganamos; no queremos salir de casa porque nos sentimos inadecuados, nos cambia el carácter, sentimos que no somos homogéneos, tendemos a deprimirnos y es cuando regresa el fantasma de nuestra soledad.

Es en esta dinámica de una cultura liviana que está inserta Latinoamérica, donde se desarrolla la despersonalización, como parte de un proceso que logra desvincular al individuo en su ser social. La construcción de la identidad va más allá de la suma de individualidades, y es la capacidad comunitaria de las mismas individualidades lo que da la interacción y puede generar el vínculo de pertenencia.

El hombre es presa de los cambios actuales, manipulado pierde su capacidad de acceder a los valores transcendentes, porque en muchos de los casos son cambiados por un proceso religioso que adormece, no representativo, no vinculante con la realidad, que acompaña la ideología imperante y que se nutre para existir de los mismos sistemas que debiera someter a una transformación profunda. Todo ello crea una ascética idealista que aleja y coadyuva a conformar un ser humano que Rojas (1994: 16) describe como:

El hombre light es frío, no cree en casi nada, sus opiniones cambian rápidamente $\mathrm{y}$ ha desertado de los valores transcendentales. Por eso se ha ido volviendo cada vez más vulnerable; por eso ha ido cayendo en cierta indefensión. De este modo, resulta más fácil manipularlo, llevarlo de acá para allá, pero todo sin demasiada pasión. Se han echo esfuerzos (...) y ya no apuntan hacia la formación de un individuo más humano, culto y espiritual, sino hacia la búsqueda del placer y el bienestar a toda costa, además del dinero.

El doctor Enrique Rojas (1994: 13ss), en su obra El hombre light, una vida sin valores nos mueve a una reflexión crítica sobre el hombre moderno, el cual modifica el comportamiento humano a tal punto que le condiciona y le depara una inestabilidad existencial que no puede ser superada con todo aquello que le rodea. El perfil psicológico del hombre "light" que nos propone es así:

(...) Se trata de un hombre relativamente bien informado, pero con escasa educación humana, muy entregado al pragmatismo, por una parte, y bastantes tópicos, por otra. Todo le interesa, pero a nivel superficial; no es capaz de hacer la síntesis de aquello que percibe, $y$, en consecuencia, se ha ido convirtiendo en un sujeto trivial, ligero, frívolo, que lo acepta todo, pero que carece de unos criterios sólidos en su conducta. Todo se torna en él etéreo, leve, volátil, banal, permisivo. Ha visto tantos cambios, tan rápidos y en un tiempo tan corto, que empieza a no saber a qué atenerse, o, lo que es lo mismo, hace suyas las afirmaciones, como "todos vale", "qué más da", "las cosas han cambiado". Y así nos encontramos con un buen profesional en su tema, que conoce bien la tarea que tiene entre sus manos, pero que 
fuera de ese contexto va a la deriva sin ideas claras, atrapado (como está) en un mundo lleno de información, que le distrae, pero que poco a poco le convierte en un hombre superficial, indiferente, permisivo, en que anida un gran vació moral.

Curiosamente si invertimos el proceso, siendo que la intención la que genere la motivación, que esta no dependiera de estímulos externos, o según Enrique Rojas (1994: 18) nos lo dice, que dependan de una "cultura nihilista", tendríamos la posibilidad de generar una verdadera conciencia que no sólo capte lo indeterminado, sino que se lance a la indeterminación y desde ahí pueda construir la identidad y con ella el pensamiento, en nuestro caso latinoamericano, y no la reproducción de uno ajeno y alienante del nuestro, sin que por ello represente un rechazo a los avances tecnológicos y a las posibilidades materiales que se puedan generar.

\section{Conformación del pensamiento latinoamericano en clave de identidad}

La construcción del pensamiento latinoamericano debe ser movida ya no por un motivo según los intereses más variados, sean comerciales, intelectuales o religiosos; debe ser movido por una voluntad que direccione las intencionalidades, que el motivo no sea el fin último de la intencionalidad, porque acabado el motivo caeríamos en el fastidio nuevamente, nuestra identidad latinoamericanamente humana debe ser movida por una voluntad biointegral y no una voluntad necrótica ${ }^{10}$; con ella nos

10 La «voluntad necrótica» encierra la dualidad que nos sume en lo estático, en lo absoluto, por ello es que podemos lanzar hacia este magma rico en indeterminación y pluriformidad reunida en un continente y llamada Latinoamérica.

La identidad es, pues, conformada no por un solo elemento, ni por un solo fenómeno, es ante todo un proceso dinámico que asuma todos los fenómenos y los transforme en hecho. El horizonte social se transforma en hecho social cuando no deja por fuera ninguno de los fenómenos que lo sustentan, es decir, el "imaginario colectivo" se nutre por medio de la capacidad simbólica de mantener lo ideológico como elemento vinculante de los individuos entre sí, legitimando a su paso el poder en cualquiera de sus manifestaciones.

De la misma forma, la historia latinoamericana es un magma del cual se nutren básicamente dos vertientes: la primera busca mantener o sustituir la ideología dominante; la segunda se basa en la "ambivalencia de los

genera la destrucción en cada ápice del ser humano, por el contrario cuando hablo de «voluntad biointegral» no generamos dualismos, pensamos la muerte como parte de la vida y esta entendida integralmente hablando, de la forma más natural, es decir integrada a la realidad, formando parte de las cosas-reales y las cosas-sentido según Xubiri (1962: 104), no por ello se contradice cuando la contraponemos a la «voluntad necrótica» es simplemente una articulación limitada dentro de un metalenguaje que por el principio de exclusión no sirve para determinar la existencia del contrario. La voluntad necrótica no mueve hacia la nada, con ella caemos en el conformismo, el lecho de muerte es cómodo, lo que no lo sería tanto deviene del conocimiento de tan hecho, todas las situaciones de muerte en el ser nos mueven a perpetuarlas, posiblemente nos sintamos cómodos, con cierta seguridad, estabilidad, sean intelectual, afectiva, religiosa u otras. Podemos agregar que en su mayoría un cadáver no abandona su ataúd una vez que se le ha declarado muerto, son muy cómodos además, están pensados para que si alguno de nosotros nos moviésemos al filo del féretro miremos una comodidad, un confort que no es otro que el mismo diseño del cementerio. Por su parte, la muerte entendida dentro de la vida, no como vida y domesticación es un nuevo "modus vivendi". 
contrarios", según Prieto (1991), en la cual se da el equilibrio que viene a manifestarse en los que buscan forjar y dejar al descubierto una historia que se genera a sí misma y no una transmitida por una "conciencia oficial", es decir, verdadera conciencia histórica.

Es claro que esta conciencia histórica tendrá, como siempre, una unidad que necesita ser síntesis de las dos vertientes y los diversos fenómenos que desde la cultura se generan, ambas y no una, la realidad histórica; nos agrade o no, el hecho es que la realidad de hoy es la simbiosis de los encuentros que consideramos como el ayer.

Hay quienes estarían interesados en hacernos creer que los conquistadores, sean estos en los tiempos de la colonia o en nuestros tiempos, eran o son los más civilizados y los aborígenes autóctonos de aquellos tiempos, los campesinos de hoy junto a los latinoamericanos comunes, no lo son tanto; o bien, que un tirano que se precia de bondad con los fondos del pueblo utilizándolos a favor de su imagen es un verdadero gobernante, esta interpretación vendría a ser la luz que depara la ceguera existencial o bien cegamos la existencia con una luz. ${ }^{11}$

Sin embargo, el peso de este devenir histórico que fomenta la identidad individual repercute a su vez en la identidad colectiva, como de hecho se da, forjándose de esta simbiosis el valor, según lo expresa Smutko ${ }^{12}$; bajo su óptica trata-

11 Carpentier citado en La reescritura de la historia en la nueva narrativa latinoamericana, de F. Ainsa, del Centro de Investigación en Identidad y Cultura Latinoamericana. Serie Conferencias, $n^{\circ} 8$, de la Facultad de Letras, Universidad de Costa Rica, p. 25.

12 Concibe la conformación de la cultura como la interacción de diversos sistemas entre los cuales se encuentra la ideología o la religión, economía, partidos políticos, mos de hacer conciencia sobre los diferentes ejes desde los cuales se gesta una cultura, en este caso la nuestra, y desde la cual se genera lo que consideramos el pensamiento latinoamericano.

La conformación de la identidad influencia un modo de ser permeando su constitución, de igual forma que reta a la razón y al espíritu; la identidad es un modo de ser pertinente a cada momento histórico ${ }^{13}$, desde el cual se construye el ser latinoamericano. Ese movimiento constante de un momento a otro no deja la posibilidad de que el ser se pueda pensar estático, dado como absoluto; el ser se construye, tanto como una motivación, desde la «voluntad biointegral» que direcciona la intención de nuestros actos, todo ello porque la identidad cambia y al cambiar se modifican los valores; así mismo, se cambian por los medios de control social que son impulsados a su vez por el ser de la colectividad que, en sentido contrario, funcionan de igual forma. ${ }^{14}$ Una vez que se constituye una cierta estabilidad el ser está permeando las identidades por medio del control

etc. Denominada "teoría del árbol cultural", aunque en realidad nunca la formuló de esta manera. En el capítulo V "Para descubrir una cultura", de su tesis, encontramos un gráfico donde la representa conformando una catedral y toda ella, esquemáticamente, sus paredes, su techo y pilares son los diferentes sistemas; a esta catedral la llama cultura. Sin embargo las conversaciones personales que mantuvimos me hicieron desprender un nuevo esquema, cuya base está sujeta a la estructura básica de su teoría. El antropólogo, Padre Gregorio Smutko OFM Cap. muere en el año 2001.

13 Cf. José Marín Cañas (1974), Realidad e imaginación.

14 Raúl Fornet (1994) nos propone una construcción filosófica latinoamericana que viene a conformarse desde la pluralidad y desde la interdisciplinariedad, liberándose de las formas tradicionales de hacer filosofía; así mismo nos deja ver cómo Latinoamérica está conformada por una"constitución intercultural y no por una idea de uniformidad cultural", p. 21. 
social, pero cuando pasa mucho tiempo manteniendo una determinada estructura de ser que favorezca un determinado paradigma es cuando se comienza a pensar que es la identidad la que se nutre del ser y este se concibe como un absoluto, dando como consecuencia lo que nos acontece.

Decíamos que los valores cambian porque los significados ya no son representativos. Y no lo son porque han perdido el enlace afectivo del sujeto con su objeto; según nos los presenta el Dr. Ramón Romero (1999: 169), este enlace puede ser: "otra persona, un grupo, organización de cualquier tipo, una idea...", por ende cuanto más se identifique el sujeto con su objeto, más significativo será este para él. "La identidad está permanentemente conquistándose, ganándose, está siempre haciéndose...", es decir, la identidad en "el pasado aún no se ha superado, y en el presente de las vivencias reales... hay elementos definitorios de la identidad..."

La identidad se constituye en cuanto no es un proyecto acabado, está ahí, se significa en cuanto es mutación, es dejar de ser y ser en un proceso constante, que aunque evolucione no deja de ser en ninguno de sus instantes, es indeterminación, es cuando se significa, es cuando caduca la significación e inicia su nueva significación.

Este es el quehacer del pensamiento latinoamericano desde Latinoamérica, un proyecto, según lo evidencia el Dr. Serrano Caldera ${ }^{15}$, que tiene como asidero nuestra visión de mundo y por ende nuestra interpretación, lo que daría como resultado el nacimiento de una filosofía latinoamericana, tanto como una teología, sociología, etc., ya no como se hacía tradicionalmente; nos dice: "para América Latina, sino desde América Latina para el resto del mundo...".

Es posible que en el afán de la especialización de cada disciplina se quiera aislar su objeto de estudio con el sentido de interpretar o estudiar dicho objeto; por ende, el discurso científico, sea este sociológico, antropológico, filosófico, teológico, somático ó psíquico. Pero es cuando se comete un grave error dado que estos discursos pueden llevarse a los más altos niveles de abstracción conceptual, dejando de lado la realidad total y la relacionalidad con muchas otras disciplinas; se genera un conocimiento aislado, que no por ello desmerezca su virtud de rigurosidad o de veracidad parcial por su aislamiento, sino en cuanto conocimiento desvinculante.

Si bien se han dado grandes logros desde estas ópticas particulares en la conformación de la identidad y del pensamiento latinoamericanos, no se pueden dar estos tipos de parcialismos, pues su realidad se conforma en la pluricidad de fenómenos. Para nuestros efectos hacemos notar que 1o "religioso" no es una resina que se mezcla históricamente, es parte del ser histórico latinoamericano, sea antes, durante y después de los diversos proyectos de conquista, y que de ninguna manera deja de ser un elemento manipulado o manipulador de lo ideológico.

15 En su visita a la Universidad Nacional, conferencias sobre la filosofía en América Latina auspiciadas por el Doctorado en Pensamiento Latinoamericano, 2000. 


\section{Identidad desde lo particular y la diversidad latinoamericana}

Todos los autores que ha generado Latinoamérica, sean estos de las más diversas corrientes, de los siglos que sean, de los tiempos y pensamientos más diversos, compatibles o antagónicos, de igual forma crean identidad, filtran desde sus estructuras identitarias y sus paradigmas individuales, ${ }^{16}$ llevan de una u otra forma la impronta de una estructura arquetípica que idealiza el ser de una identidad, que se construye desde su visión de mundo, se mantiene y se va descubriendo, de la misma forma que se sucede un cambio paradigmático sin que la estructura existente lo perciba o lo permita.

Zidane Ziraqui (2000: 30) nos dice que:

El momento crucial entre la crisis del paradigma imperante y el surgimiento de uno nuevo, es la fase prerrevolucionaria. Mientras dura el tránsito del paradigma el modelo lleva adquirir un aspecto ambiguo. Entre el paso de una ciencia normal a otra ciencia, o de un antiguo paradigma a otro nuevo, la sociedad transita por un estado de incertidumbre, de confusión entre lo nuevo y

16 Interpretamos "paradigma" desde la exposición de Zidane Ziraqui (2000: 28ss), quien toma de Kuhn “... el sentido actual de paradigma: toda ciencia se desarrolla con base en un paradigma subjetivo que es la esencia de la misma ciencia, que sustenta los modos de ser y de pensar de la sociedad donde se desenvuelve esa misma ciencia... interpretado como un conjunto de valores compartidos... el paradigma no es un reflejo de la realidad, más bien el paradigma permite crear nuestra propia realidad... el modelo predominante no logra explicar (la realidad)...no es más verdadero que el anterior sino más explicativo..." desconcertante, por un lado, y o viejo y conocido por el otro.

El ser social se construye también desde lo ideológico, y este a su vez se sustenta en la dinámica del "imaginario colectivo", que por su parte no es un depósito estático, es en sí mismo un ente interactual y dinámico que se relaciona con el ser particular de la misma forma que con el ser colectivo a partir de la intuición selectiva de la conciencia, que le permite nutrirse del magma conformado por la imágenes conceptuadas que circundan y pululan la atmósfera literaria del hecho social, una lectura que no siempre ha llegado, o llega, por los medios escritos, sino a través de la vivencia como lectura vital de la existencia.

En ella, la existencia, no podemos dejar de lado la narrativa creativa de los poetas que influye en lo más profundo del corazón humano, en el arte de correr la voz por los pasillos del alma, de ser don de la traducción del silencio a la palabra, del terror a la alegría, de la muerte o la vida, siendo que de esta forma llegan a tratar la realidad de "lo religioso" desde una sensibilidad enigmática capaz de reflejar la intimidad del hombre en su totalidad, como lo hace el poeta nicaragüense Alfonso Cortés (18931969) cuando nos declama desde su locura y aislamiento, y encadenado a una viga de la casa escribe:

¡La distancia que hay de aquí a una estrella que nunca ha existido porque Dios no ha alcanzado a pellizcar tan lejos la piel de la noche $;$ Y pensar que todavía creemos que es más grande o más útil la paz mundial que la paz 
de un solo salvaje...

(La canción del espacio, 1927) ${ }^{17}$

Nos ocasiona un placer que nos nutre y nos devasta, nos da la posibilidad de crear nuestro propio futuro, podemos pensar a Dios, aun cuando muchos insisten en afirmar que es lo impensable e impenetrable; pensar nuestra identidad, es pensar «lo religioso» como parte de lo político, lo económico, lo social. Muchos han logrado lo que Serrano Caldera declara "un proceso de contradicción sin síntesis".

No menos se puede decir de Jorge Debravo poeta turrialbeño ${ }^{18}$ desde su sensibilidad social; de Carmen Lira desde su intelecto abierto apoyada en una visión creativa a favor de una sociedad más justa, sin perder su comunicación con los infantes, o bien desde la destreza creativa de Yolanda Oreamuno a la cadencia sutil de Eunice Odio, la fuerza de José Coronel Urtecho, la profundidad ideológica del "Maestro" José Martí, la fuerza revolucionaria de Simón Bolívar. Así mismo, el poder creador de García Márquez, la delicadeza astuta de Sábato, la pasión melancólica de José León Sánchez, la riqueza exótica de Sepúlveda, la sensibilidad romántica de Pablo Neruda, la profundidad social de Carmen Naranjo, la vitalidad ceremonial de Rubén Darío, la agudeza social de Augusto Thiel,

la sensibilidad cotidiana de Cortázar, la búsqueda filosófica de Zea o la palabra liberadoramente humana de Octavio Paz;

17 Ernesto Cardenal (1998), Flor y canto: antología de la poesía nicaragüense, Centro Nicaragüense de Escritores. p. 33-41. El poema del cual extraemos un fragmento fue el primer poema escrito desde su locura.

18 Dícese del nativo de Turrialba, Costa Rica. junto a ellos muchos otros, miles de otros, que se vierten en su palabra, en su prosa, en su construcción eidética, en su poesía, en su magia, en su naturaleza existencial.

Vertida en toda ella, sus sueños y temores, su conciencia pregrabada y la evolución de sus verdaderas conciencias, su historia externa espacio-temporal, junto a su historia interna afectiva, psíquica, intelectual; todas estas fuerzas se dejan sentir en sus vidas, $y$ no menos en sus escritos, en sus palabras, las luces y las sombras de sus demonios, desde su dimensión de pecado, libertad, erotismo, moralidad, su pensamiento político, religioso, social condensado en la vida cotidiana de estos hombres y mujeres cuyo legado es parte de la conformación del pensamiento latinoamericano, una identidad que no se reduce a un fenómeno aislado, por el contrario, como nos dice Margarita Camera (1999: 71) en su ensayo:

Latinoamérica es un desborde de realidades que llegan sin embargo a confluir en un solo océano, el de la palabra (indígena, africana, española, portuguesa): la cual contiene parte esencial de la identidad. De allí la diversidad de artes, de literatura, la policromía y la multitud de afluencias en los matices de los seres que habitan los confines latinoamericanos.

Nuestra identidad se vierte en miles de hombres y mujeres que forjan con sus vidas sus propios pasos y los pasos de muchos otros en nuestro continente; a este “almacén" multiétnico y polifacético le llamamos pensamiento latinoamericano, no sólo al quehacer de la política, la economía, el arte, sino también al quehacer 
religioso, pues todo ello vive en el ser del hombre, cada vertiente que alimenta su alma lo determina y lo potencializa.

No buscamos hacer un tratado de teología, filosofía o sociología; sólo partimos del hecho social, buscamos pues, determinar cómo a la luz de los métodos y la praxis catequética, el ser de la Iglesia latinoamericana influye de manera determinante en la conformación de la identidad tanto como en la conformación del pensamiento latinoamericano, siendo esta el instrumento de dominación ideológica más efectivo desde la conquista hasta nuestros días.

Poco a poco seremos más que sueños desvelados en los espacios vacíos de la historia, segmentada, manipulada, ajada y autorizada. Seremos tan reales porque somos parte de la misma naturaleza. Somos todos, los que fuimos, los que estamos y los que vendrán, somos constructores de nuestras identidades, somos pensamiento latinoamericano cuando nos explicamos a nosotros mismos, y aunque la reflexión se extienda desde la particularidad de uno o de muchos individuos en un espacio-tiempo determinado, no es fruto de ese uno, o de esos muchos, la reflexión es producto de todos, y de hecho, tiene muchos rostros y muchas voces que se suceden, pero que son parte de un solo ser.

\section{Bibliografía}

Ainsa, F. (s.f.). La reescritura de la historia en la nueva narrativa latinoamericana. San José: CIICLA, Universidad de Costa Rica.

Boff, L. (1999). Los sacramentos de la vida. España: Sal Térrea.
Camena, M. (1999). Latinoamérica desborde de realidades. En Oscar León Palacios (ed.). Pensamiento filosófico contemporáneo en América Central. Guatemala

Cardenal, E. (1998) (comp.). Flor y canto: antología de la poesía nicaragüense. Managua: Centro Nicaragüense de escritores.

Darwin, C. (1963). El origen del hombre y la selección en relación al sexo. $6^{\mathrm{a}}$. Ed. México: Diana.

Elias, N. (2000). Teoría del símbolo. Barcelona: Península.

Forvet-Betancourt, R. (1994). Hacia una filosofía intercultural latinoamericana. San José: DEI.

Fromm, E. (1963). Ética y psicoanálisis. $4^{\mathrm{a}}$. Ed. México: FCE.

Harris, L. (1985). Evolución, génesis y revelaciones. Madrid: Hermann Blume.

Hawking, S. (1988). Historia del tiempo del big bang a los agujeros negros. Barcelona: Crítica.

Marín Cañas, J. (1974). Realidad e imaginación. San José: Hombre y Sociedad.

Popol Vuh: Las antiguas historias del Quiché (1976). 5ª . Ed. Adrián Recinos (trad.). San José: EDUCA.

Prieto, E. (1991). Mi pueblo. San José: Editorial Universidad de Costa Rica.

Rojas, E. (1994). El hombre Light, una vida sin valores. Santiago (Chile): El Planeta.

Romero, R. (1999). Identidad: nace en Honduras una reflexión filosófica. En Oscar León Palacios (ed.). Pensamiento filosófico contemporáneo en América Central. Guatemala.

Rosseau, J.J. (1972). El origen de la desigualdad entre los hombres. México: Grijalbo. 
Serrano Caldera, A. (1994). El rostro de la posmodernidad. San José: EL amanecer/ CSUCA.

Tagose, R. (1998). Obras selectas. Vol. I. Barcelona: Edicomunicación.
Xubiri, X. (1962). Sobre la esencia. Madrid: Sociedad de Estudios y publicaciones.

Ziraqui, Z. (2000). La crisis de los paradigmas en la modernidad y posmodernidad. México: Noriega. 

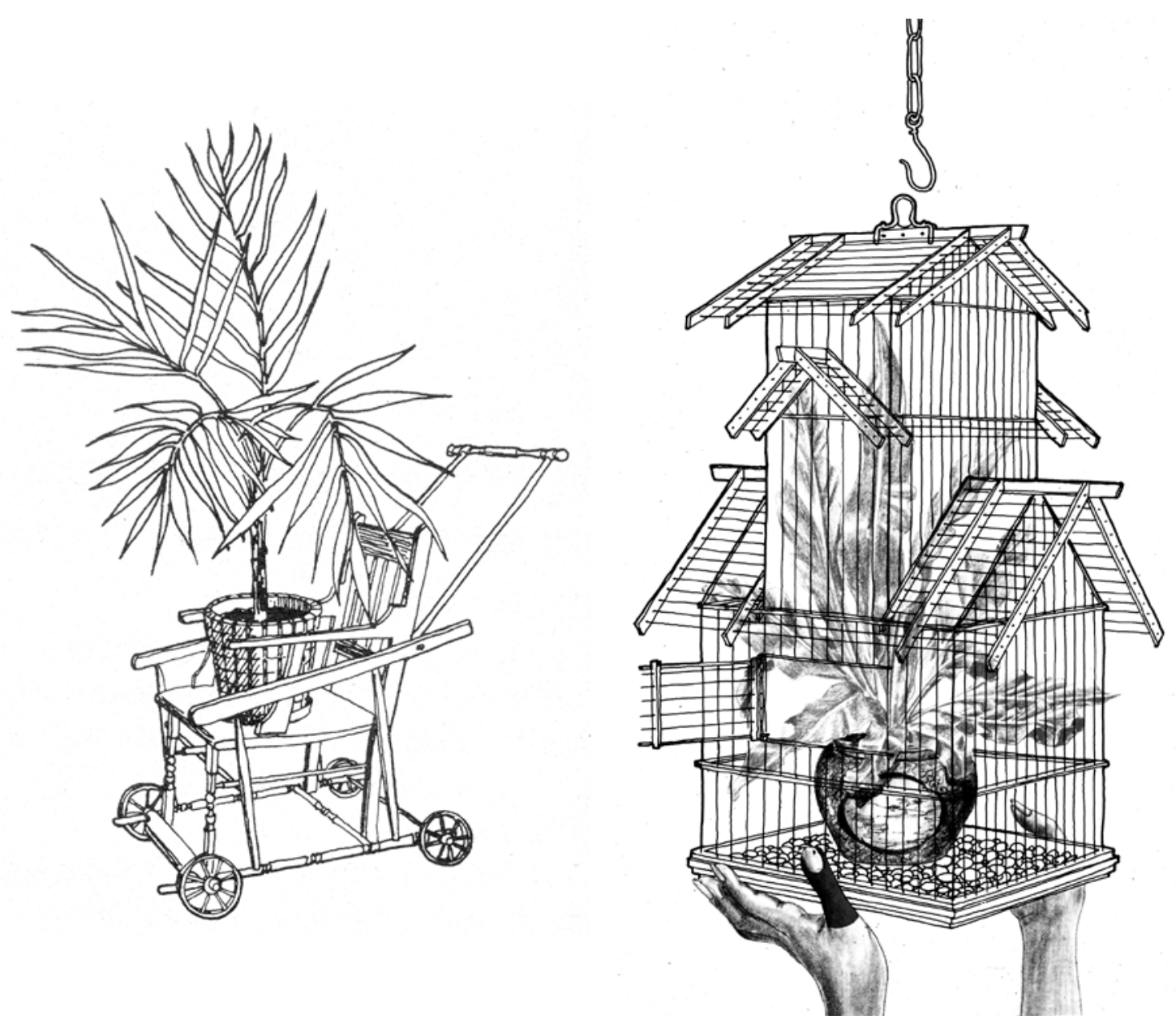

Sergio Rojas Chaves

Sujetos y alternativas

Ilustración digital 